\title{
The accessory obturator nerve: an anatomical study with literature analysis
}

\author{
Mehmet Turgut ${ }^{1}$, Matthew Protas ${ }^{2}$, Brady Gardner $^{3}$, Rod J. Oskouian ${ }^{3}$, Marios Loukas $^{2}$, R. Shane Tubbs ${ }^{2,3}$ \\ ${ }^{\prime}$ Department of Neurosurgery, Adnan Menderes University School of Medicine, Aydin, Turkey \\ ${ }^{2}$ Department of Anatomical Sciences, St. George's University, Grenada, West Indies \\ ${ }^{3}$ Seattle Science Foundation, Seattle, WA, USA
}

\begin{abstract}
Objectives: The accessory obturator nerve (AON) is often underrepresented in the literature and unknown to many surgeons. As this variant nerve has been mistaken for other regional nerves e.g., obturator nerve, nerve injury has occurred. Therefore, the current study was undertaken to better understand the surgical anatomy of the AON.

Methods: In the supine position, 20 adult fresh frozen cadavers (40 sides) underwent an anterior approach to the retroperitoneal space. When present, the length and diameter of the AON were measured with microcalipers. The position, course and origin of each $A O N$ were documented.

Results: The AON was identified on 12 sides (30\%). The origin was found to be L2-L3 on four sides; L3 on two sides, L3-L4 from three sides, from the obturator nerve on two sides, and from the femoral nerve on three sides. The average length from the origin to the superior pubic ramus was $14.5 \mathrm{~cm}$. The average diameter was found to be $1.2 \mathrm{~mm}$. All AON were found to lie medial to the psoas major muscle. Additionally, on all sides, the AON was medial to the femoral nerve and lateral to the obturator nerve. Two left sides anastomosed with the anterior division of obturator nerve at its exit from the obturator foramen. Eight sides terminated deep (two) or superficial (six) to the origin of pectineus; two of these had demonstrable branches to the hip joint.

Conclusion: The AON is a normal anatomical variant and there are many variations in its origin and terminal branches can be "strong" or "weak." Knowing the normal anatomy and variations of the AON is important for surgeons including neurosurgeons, orthopaedic surgeons, and urologists who deal with the pathologies of this area.
\end{abstract}

Keywords: anatomy; lumbar plexus; posterior abdominal wall; psoas major; variations

Anatomy 2017;11(3):121-127 @2017 Turkish Society of Anatomy and Clinical Anatomy (TSACA)

\section{Introduction}

The accessory obturator nerve (AON) (Figure 1) was first described in 1672 by Isbrand van Diemerbroeck. ${ }^{[1]} \mathrm{He}$ reported that it was found in roughly one out of every three persons and originated from the third and fourth lumbar nerves. ${ }^{[1]}$ Not until 1794 was it described in detail by Schmidt (1794). Since its discovery, it has been called the anterior internal crural nerve, accessory nerve of the internal crural nerve, and the nerve of the coxo-femoral articulation. ${ }^{[2]}$ Some have proposed that it should be named the accessory femoral nerve owing to its typical derivation from the posterior part of the anterior division of L3 and L4, its function, and its anatomicalcourse over the pubic ramus. ${ }^{[3]}$
The lumbar plexus is derived from the ventral rami of L1-L4, often with a contribution from T12. ${ }^{[4]}$ The obturator nerve is most commonly derived from the $\mathrm{L} 2$ to $\mathrm{L} 4$ ventral rami. ${ }^{[4]}$ The AON is described in Katritsis et al. ${ }^{[5]}$ as being derived from the posterior part of the anterior division of $\mathrm{L} 3$ and L4. Typically, the AON passes alongside the obturator nerve toward the obturator foramen. Instead of passing through this foramen, it passes over it. There are multiple variationsof the terminal branches of the $\mathrm{AON}$ after it passes over the superior pubic ramus (Tables 1-3). ${ }^{[5-16]}$

Knowledge of the AON and its variations can be important to surgeons, especially regarding anterior and lateral approaches to the spine. ${ }^{[17-19]}$ Misidentification of the nerve can also lead to injury. ${ }^{[20]}$ 


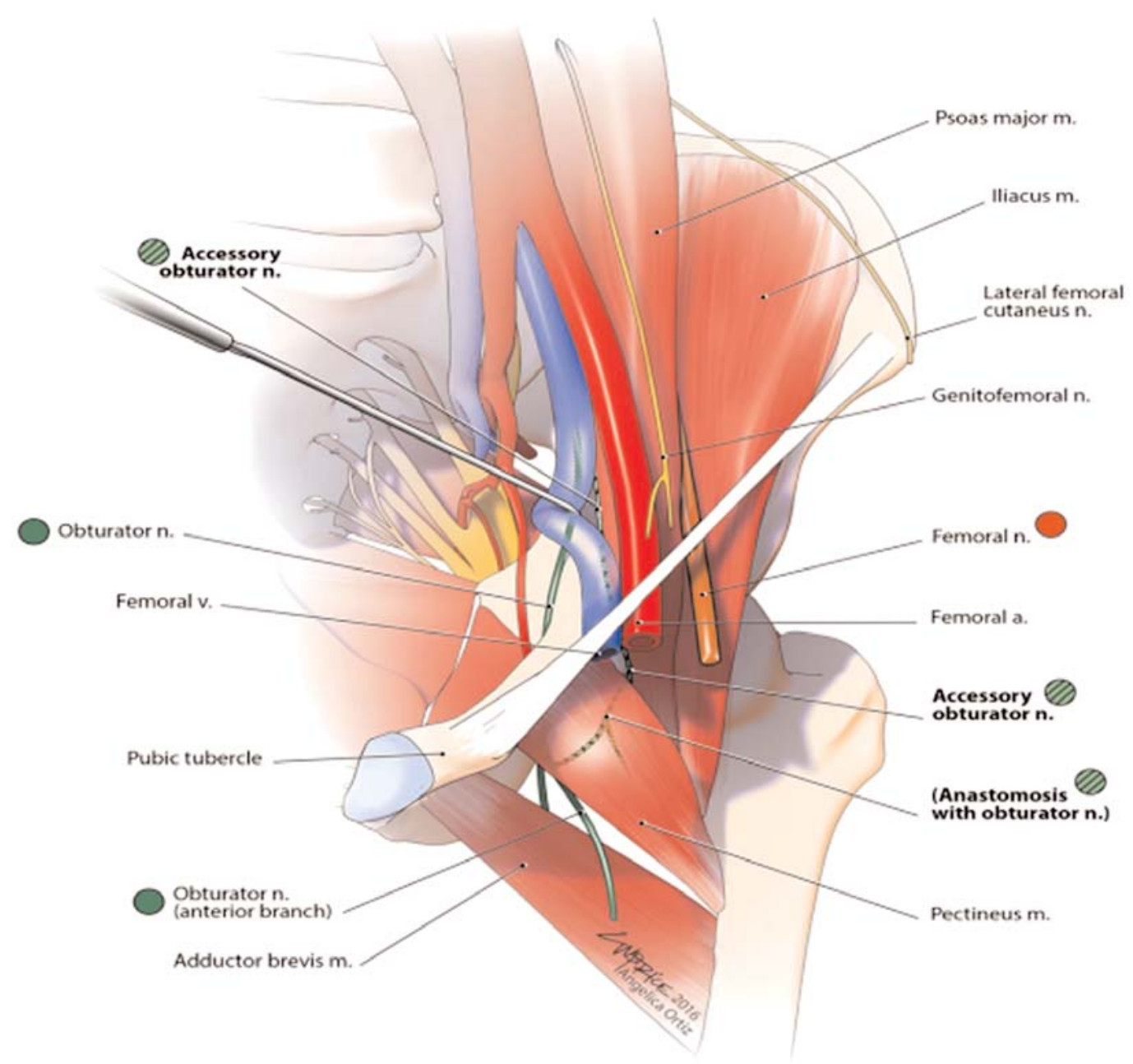

Figure 1. Schematic drawing of the accessory obturator nerve and surrounding anatomy. [Color figure can be viewed in the online issue, which is available at www. anatomy.org.tr]

\section{Materials and Methods}

In the supine position, 20 adult fresh frozen cadavers (40 sides) underwent an anterior approach to the retroperitoneal space. Twelve specimens were females and eight were males. Using standard dissection techniques, the abdominal viscera were mobilized and retracted. Once the overlying psoas fascia was identified, it was entered and the psoas major muscle retracted laterally. The obturator nerve was located and the region surrounding it carefully dissected to ascertain the presence of an AON. When present, the length and diameter of the $\mathrm{AON}$ were measured with microcalipers. The position, course and origin of each AON were documented. Statistical analysis between sides and sex were performed with Statistica for Windows (version 10.0; StatSoft Inc., Tulsa, OK, USA) with statistical significance set at $\mathrm{p}<0.05$.

\section{Results}

The AON was identified on 12 sides (eight male/ four female) (30\%) (seven left/ five right) (two specimens bilateral: both male) (Figure 2). The origin was found to be L2-L3 on four sides; L3 on two sides; L3-L4 from three sides; from the obturator nerve ontwo sides; and from the femoral nerve onthree sides (Figure 3). The average length from the origin to the superior pubic ramus was $14.5 \mathrm{~cm}$ (range: $11-18.5 \mathrm{~cm}$ ). The average diameter was found to be $1.2 \mathrm{~mm}$ (range: $0.8-1.5 \mathrm{~mm}$ ). All AON were found to lie medial to the psoas major muscle. Additionally, on all sides, the AON was medial to the femoral nerve and lateral to the obturator nerve. Two left sides anastomosed with the anterior division of obturator nerve at its exit from the obturator foramen (Figure 4). This conjoined nerve then traveled as does the normal 
obturator nerve course. Eight sides terminated deep (two) or superficial (six) to the origin of pectineus; two of these had demonstrable branches to the hip joint, i.e., piercing the iliofemoral ligament. One side terminated on periosteum of pubic bone (Figure 5). Two AON gave branches to the psoas major within the pelvis (Figure 5). Branches that became very small in caliber and terminated at the superior pubic ramus were termed "weak" branches (Figure 5) and those that were robust and continued beyond the superior pubic ramus as larger branches with multiple branches so of which continued to the obturator nerve where referred to as "strong" branches (Figure 4). No branches to adductor longus were found. No statistical significance was found when analyzing for side or sex.

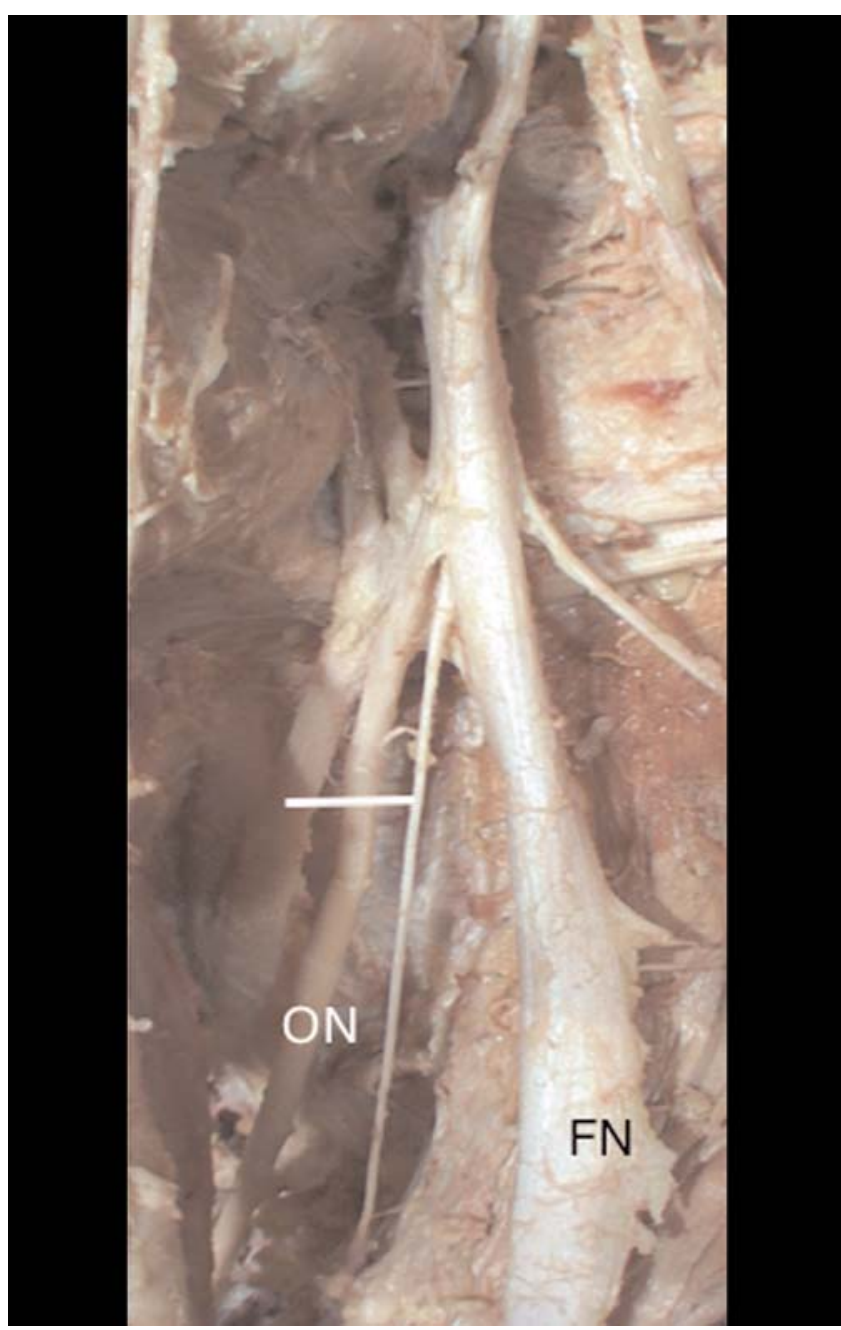

Figure 2. Left cadaveric example of an accessory obturator nerve (arrow) arising at the junction of the obturator (ON) and femoral nerves (FN). [Color figure can be viewed in the online issue, which is available at wnw. anatomy.org.tr]
Table 1

Quantitative analysis of each study reporting the prevalence of the AON.

\begin{tabular}{|c|c|c|c|c|}
\hline & $\begin{array}{c}\text { Prevalence } \\
\text { of AON }\end{array}$ & $\begin{array}{c}\text { Plexus } \\
\text { examined }\end{array}$ & $\begin{array}{c}\text { Male } \\
\text { prevalence }\end{array}$ & $\begin{array}{c}\text { Female } \\
\text { prevalence }\end{array}$ \\
\hline Eisler $^{[6]}$ & $25 \%$ & 32 & & \\
\hline Eisler $^{[7]}$ & $29 \%$ & 120 & & \\
\hline Bardeen $^{[8]}$ & $8.4 \%$ & 250 & & \\
\hline Kaiser ${ }^{[9]}$ & $8.3 \%$ & 24 & & \\
\hline Woodburne ${ }^{[10]}$ & $8.7 \%$ & 550 & & \\
\hline Webber $^{[11]}$ & $8 \%$ & 50 & & \\
\hline Katritsis $^{[5]}$ & $13.2 \%$ & 1000 & $13.3 \%$ & $12.9 \%$ \\
\hline Akkaya ${ }^{[12]}$ & $12.5 \%$ & 24 & & \\
\hline Anloague and Hijibregt ${ }^{[13]}$ & $8.8 \%$ & 30 & & \\
\hline Average & $13 \%$ & 2080 & & \\
\hline
\end{tabular}

Table 2

Sites of origin of the AON.

\begin{tabular}{|c|c|c|}
\hline Study & Origin & Prevalence \\
\hline Quain $^{[14]}$ & Anterior crural nerve & Two cases \\
\hline Ellis $^{[15]}$ & Trunk of the obturator nerve & - \\
\hline \multirow[t]{5}{*}{ Katritsis et al. ${ }^{[5]}$} & L3-L4 & $63.60 \%$ \\
\hline & L2-L4 & $10.60 \%$ \\
\hline & L2-L3 & $7.60 \%$ \\
\hline & L3 & $6.10 \%$ \\
\hline & Trunk of the obturator nerve & $12.10 \%$ \\
\hline
\end{tabular}

Table 3

Reported terminal branches of the accessory obturator nerve.

\begin{tabular}{|c|c|c|}
\hline Study & Terminal branches & Prevalence \\
\hline Quain $^{[14]}$ & $\begin{array}{l}\text { Sensory cutaneous branch } \\
\text { of inner thigh }\end{array}$ & \\
\hline Allen and Shakespeare ${ }^{[16]}$ & $\begin{array}{l}\text { Anastomosing with obturator } \\
\text { nerve and supplying skin on } \\
\text { inner thigh }\end{array}$ & \\
\hline \multirow[t]{3}{*}{ Woodburne ${ }^{[10]}$} & Adductor longus & \\
\hline & Pectineus muscle sole innervation & \\
\hline & $\begin{array}{l}\text { Pectineus muscle duel innervation } \\
\text { (femoral) }\end{array}$ & \\
\hline \multirow[t]{5}{*}{ Katritsis et al. ${ }^{[5]}$} & Anterior branch of the obturator nerve & $14.30 \%$ \\
\hline & Posterior branch of the obturator nerve & $4.65 \%$ \\
\hline & Trunk of the obturator nerve & $6.10 \%$ \\
\hline & Femoral nerve & $2.30 \%$ \\
\hline & Hip joint & \\
\hline
\end{tabular}




\section{Discussion}

\section{Prevalence}

An $\mathrm{AON}$ in humans has a reported incidence of $30 \%$, ${ }^{[21]}$ which is in line with our findings. Other authors have reported an incidence range of $8 \%$ to $29 \% .^{[22]}$ Bonica $^{[23]}$ reported a prevalence of $8 \%$ to $12 \%$. In studies examining the lumbar plexus for the AON, the following was reported: $25 \%$ (of Eisler's 32 plexuses) ${ }^{[6]}$ 29\% (of Eisler's 120 plexuses), ${ }^{[7]} 8.4 \%$ (21 of Bardeen's 250 plexuses), ${ }^{[8]} 19 \%$ (De Sousa et al.), ${ }^{[2]} 8.3 \%$ (of Kaiser's 24 plexuses), ${ }^{[9]} 8.7 \%$ (of Woodburne's 550 plexuses), ${ }^{[10]} 8 \%$ (Webber), ${ }^{[11]} 11.6 \%$ (Sim and Webb), ${ }^{[25]} 12.5 \%$ (of Akkaya's 24 plexuses), ${ }^{[12]}$ and $8.8 \%$ (of Anloague and Hujijbregt's 30 plexuses). ${ }^{[13]}$ The largest study was conducted by Katritsis et al. ${ }^{[5]}$ in 1980 . Among 500 cadavers, the $\mathrm{AON}$ was found in $13.2 \%$ (13.3\% of males and $12.9 \%$ of females) with predominance on the left side of the body. ${ }^{[5]}$ Sim and $\mathrm{Webb}^{[25]}$ also noted a more frequent occurrence on the left side and in females. Akkaya ${ }^{[12]}$ reported an incidence of three AON in 12 cadavers (four males, eight females). One female patient presented with it bilaterally.

\section{Origin}

In our study, the origin of the AON was found to be L2L3 on four sides; L3 on two sides; L3-L4 from three sides; from the obturator nerve on two sides; and from the femoral nerve on three sides Katritsis et al. ${ }^{[5]}$ found it to be formed by roots from the anterior primary divisions of L3 and L4 (63.6\%) or L2, L3 and L4 (10.6\%), or L2 and L3 $(7.6 \%)$, or L3 $(6.1 \%)$, or from the trunk of the obturator nerve $(12.1 \%)$. Ellis ${ }^{[15]}$ found only one case in which the AON arose from the trunk of the obturator nerve. Quain ${ }^{[14]}$ described the origin of the obturator nerve in two cases.

\section{Course}

In $100 \%$ of the plexuses with an AON examined, Katritsis et al. ${ }^{[5]}$ found that it passed $2-3 \mathrm{~cm}$ anterolateral to the obturator nerve and medial to the psoas major towards the obturator foramen, but instead of passing through the canal it passed over the superior pubic ramus, staying medial to the psoas muscle. Woodburne ${ }^{[10]}$ described the $\mathrm{AON}$ as passing directly over the pubic ramus under the femoral vein. Various authors have described that once it has passed over the pubic ramus, the nerve descends dorsally to the pectineus muscle, where it typically separates into three branches: one entering the anterior hip joint, one entering the dorsomedial aspect of the pectineus muscle, and one passing medially to anastomose with the anterior branch of the obturator nerve. ${ }^{[10,26]}$ A rare case was reported by Rohini et al. ${ }^{[19]}$ in which the AON divided into

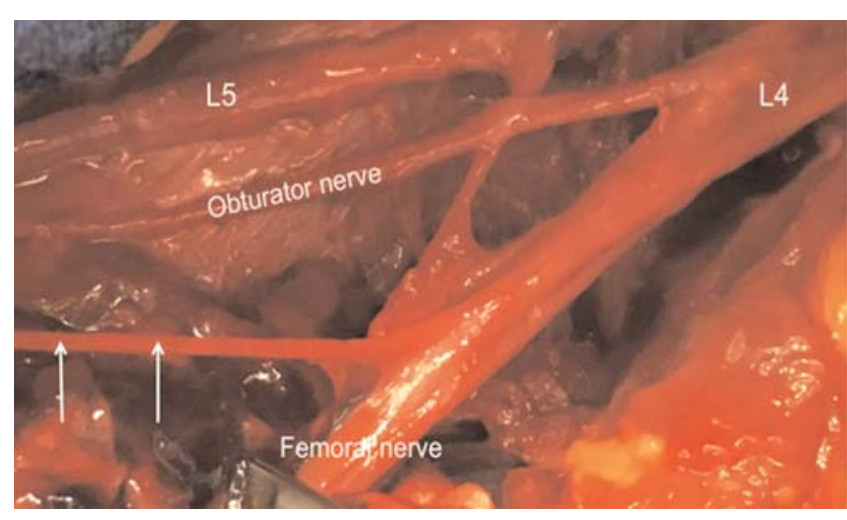

Figure 3. Accessory obturator nerve (arrows) arising from the femoral nerve. [Color figure can be viewed in the online issue, which is available at www. anatomy.org.tr]

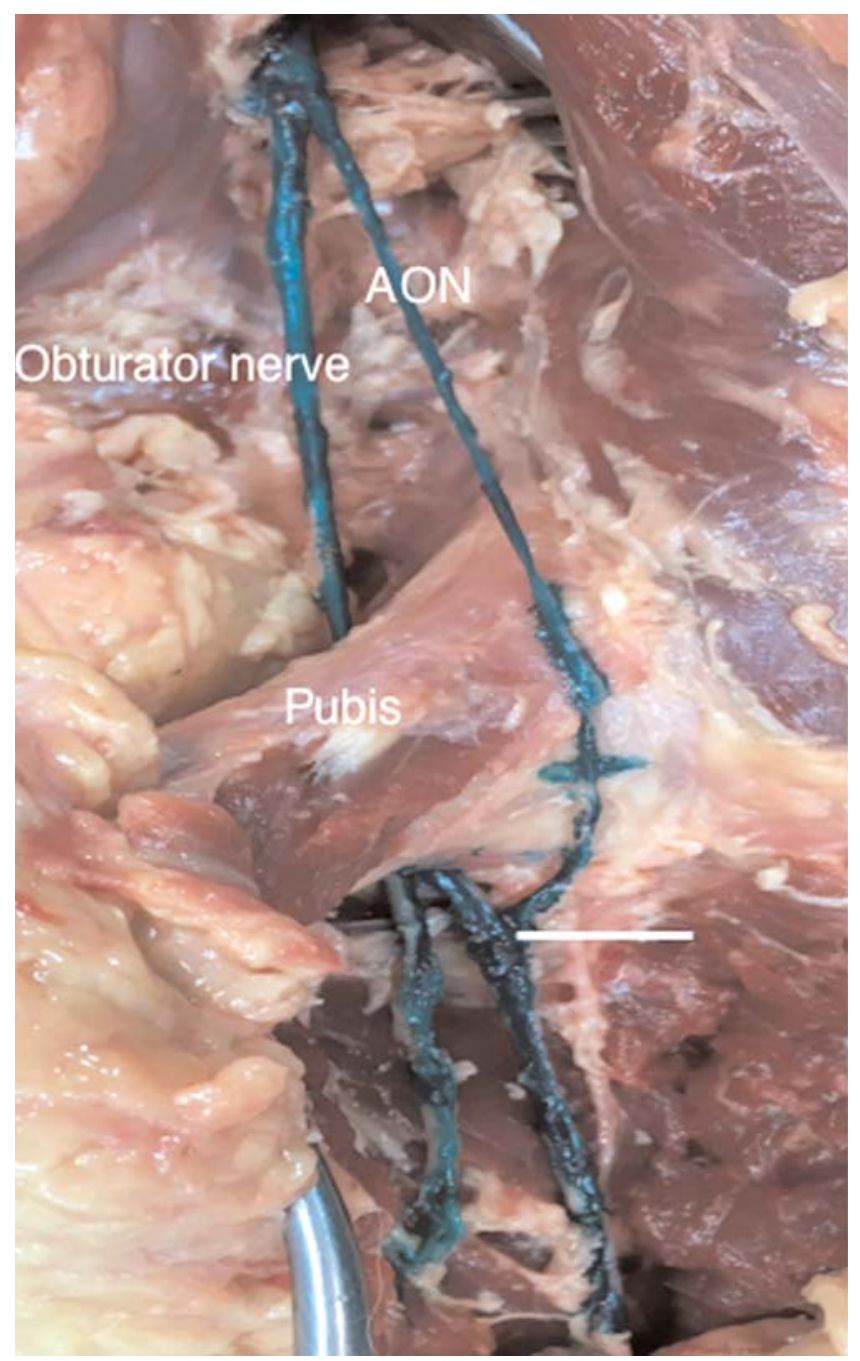

Figure 4. Accessory obturator nerve (AON) coursing over the pubis and anastomosing (arrow) with the anterior branch of the obturator nerve. [Color figure can be viewed in the online issue, which is available at www. anatomy.org.tr] 
three typical terminal branches, and passed superficially to the pectineus muscle instead of deep to it.

Multiple variations of the three terminal divisions have been reported. Katritsis et al. ${ }^{[5]}$ saw that after supplying the pectineus, the AON branched off behind that muscle, supplying the anterior branch of the obturator nerve (14.3\%), posterior branch of the obturator nerve ( $4.65 \%)$, trunk of the obturator nerve $(6.1 \%)$ and femoral nerve $(2.3 \%)$. Woodburne ${ }^{[10]}$ also reported that a single branch supplying the adductor longus is not uncommon, along with other additional branches. A very common variation of the $\mathrm{AON}$ is as the sole innervation of the pectineus muscle, rather than the typicaldual innervation with the femoral nerve. ${ }^{[10]}$ Quain ${ }^{[14]}$ described a small cutaneous branch that supplies the inner thigh and upper proximal inner leg. Allen and Shakespeare ${ }^{[16]}$ reported a similar finding of the $\mathrm{AON}$ anastomosing with the obturator nerve and supplying cutaneous innervation to the skin of the inner thigh. In one case reported by Tubbs et al., ${ }^{[27]}$ a pseudoganglion was found in association with an AON.

\section{Landmarks}

Akkaya $^{[12]}$ reported that the mean distance of the AON from the femoral nerve was $1.6 \mathrm{~cm}, 2.0 \mathrm{~cm}$ superior and 2.0 $\mathrm{cm}$ anterior to the upper wall of the external opening of the obturator canal, $4.0 \mathrm{~cm}$ from the pubic tubercle, and $4.6 \mathrm{~cm}$ from the median plane. Although no measurements of the AON have been reported, it is described as "smaller than the usual obturator nerve". ${ }^{[10,14,26]}$ Better estimates of the size of the nerve could help in identifying it.

\section{Anatomy}

In the past, the prevalence of the AON has consistently been reported as ranging from $10 \%$ to $30 \% .^{[10,21,22]}$ Individual studies have involved samples too small for the prevalence of the AON in the population to be estimated reliably. When data from previous studies were combined, the AON was present in 13\% (273 of 2,102 plexuses: Table 1). Most studies failed to record a gender or unilateral bias. However, Sim and $\mathrm{Web}^{[25]}$ and Akkaya et al. ${ }^{[12]}$ reported a greater female and left sided prevalence. These resultscould be misleading owing to the paucity of specimens. In the largest study by Katritsis et al ${ }^{[5]}$ in which 1000 plexuses were examined, there was no apparentdifferencebetween males and females in the prevalence of an $\mathrm{AON}$ in the lumbar plexus. However, there was still a left sided dominance in unilateral cases. This suggests no association of sided dominance with gender.

Most reports describe the AON as arising from $\mathrm{L} 3$ and L4 (Table 2). Katritsis et al. ${ }^{[5]}$ studied 1000 plexuses (132 plexuses with $\mathrm{AON}$ ) and found that $36.4 \%$ of $\mathrm{AON}$ show variations of the typical origin. Although most of these variations are not drastically different, it is important to acknowledge that the AON can derive from the trunk of the obturator nerve or the anterior crural nerve. ${ }^{[14]}$ The AON branching from the trunk of the obturator nerve $\left(12.1 \%\right.$ : Katritsis et al. $\left.{ }^{[5]}\right)$ refutes the notion that it should be termed the accessory femoral nerve. Misidentification of the AON can lead to surgical complications such as those in a case reported by Jirsch and Chalk ${ }^{[20]}$, which demonstrated the importance of understanding these variations in surgical practice. In this case, the AON was thought to be the obturator nerve, which led to the obturator nerve being injured during elective laparoscopic tubal occlusion. Techniques such as MRI and intraoperative nerve stimulationcan help to localize it. ${ }^{[12]}$

\section{Embryology}

There are conflicting hypotheses about the embryological origin of the AON. The original view is that the AON is derived from a splitting of the obturator nerve caused by the developing obturator foramen. ${ }^{[10]}$ This was questioned

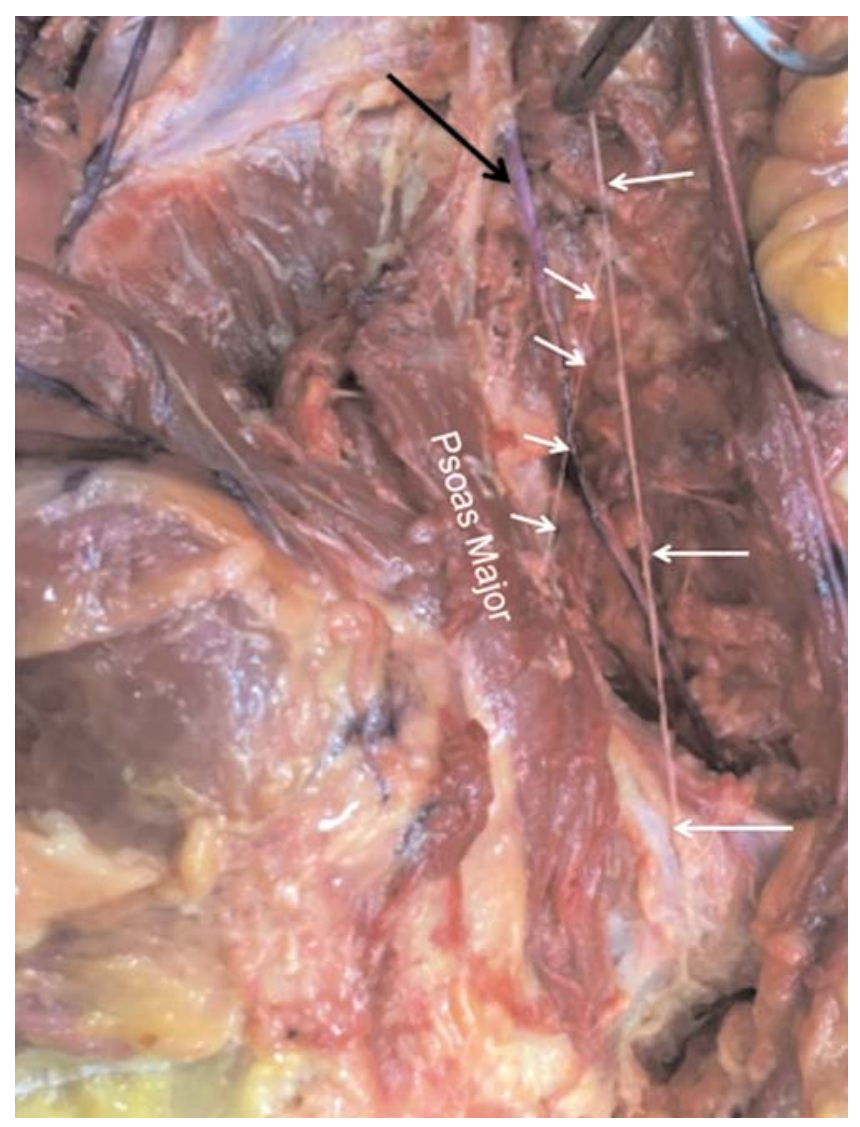

Figure 5. Right sided accessory obturator nerve (right arrows) giving rise to a branch (left arrows) to the psoas major muscle. [Color figure can be viewed in the online issue, which is available at www. anatomy.org.tr] 
by the observation that the pubis develops around the obturator nerve, enclosing it in the obturator foramen. ${ }^{[10,28]}$ Howell $^{[2]}$ also asserted that when the pubis develops around the obturator nerve, thus separating it from the AON. Yasar et al. ${ }^{[2]]}$ reported an AON in four of 20 lumbar plexuses in 10 fetuses between the gestational ages of 24 and 28 weeks. Woodburne ${ }^{[10]}$ described the pectineus as a "border muscle" in embryological development. This is because it is located between the muscles typically innervated by the obturator and femoral nerves. It is located in the anterior thigh but has a function similar to that of an adductor medial thigh muscle. The development of this muscle and its innervation leaves further questions as to whether the AON and its innervation of this border muscleis more closely representative of the femoral or obturator nerve. The AON innervates the pectineuson its dorsomedial aspect, while the femoral branch arises distally to the inguinal ligament, turns medially, travels dorsal to the femoral vessels, and finally innervates the muscle on the ventrolateral aspect. ${ }^{[10]}$ With this in mind, the arguments about naming the AON the accessory femoral nerve are questioned by the similar way in which the pectineus in innervated. Bolk ${ }^{[30]}$ described the femoral innervation as frequently being an independent branch and very loosely associated with the femoral nerve. ${ }^{[10]}$ However, Woodburne ${ }^{[10]}$ proposed that the differences in innervation could arise because of phylogenetic separation between the dorsomedial obturator portion of the pectineus muscle and the ventrolateral femoral portion. This raises questions as to whether the phylogenetic separation of the pectineus muscle could accountfor the embryological development of the AON. In a $14 \mathrm{~mm}$ embryo, a distinct branch of the femoral nerve was found to innervate the pectineus. ${ }^{[8,10]}$ Leche $^{[31]}$ proposed that during development in some mammals, there is an obturator intermedius muscle in addition to the obturator externus. He suggested that this obturatorintermedius becomes associated with the pectineus muscle, leading to dual innervation by the femoral nerve and AON. Grafenberg ${ }^{[32]}$ described a six-week-old human embryo in which the muscles of the anterior and medial thigh developed from a single primordial muscle. ${ }^{[10]}$ This primordial muscle was innervated by both the femoral and obturator nerves. Uneven splitting of it could account for the changes in nervous innervation leading to the development of the AON. Visual evidence for this was suggested by Bardeen and Elting ${ }^{[8]}$, who noticed a mass in association with the embryonic external obturator and pectineusmuscles, which he believed to be the area where the obturator nerve would innervate. Evidence supporting this hypothesis is its route and its location on the dorsal aspect of the pectineus muscle after crossing the pelvic brim and before splitting into its terminal branches. Further evidence for the formation of the AON by phylogenic separation is the atypical path over the pubic ramus (the known path for innervation of the anterior thigh muscles) instead of through the obturator canal.

\section{Clinical Implications}

Akkaya et al. ${ }^{[12]}$ reported that the presence of an AON could negatively affect the clinical efficacy of an obturator nerve block. He stated that if the patient has an $\mathrm{AON}$, it could be necessary to block this as well. AON blockage can be recommended for thigh surgeries, treatment of pain, and diagnosis of hip joint pain. ${ }^{[19]}$ Akkaya et al. ${ }^{[12]}$ showed that the location of the AON in 12 cadavers was a mean distance of $4 \mathrm{~cm}$ lateralto the pubic tubercle, which should be used as a guide for AON block. Positioning for an AON block should be $2 \mathrm{~cm}$ lateral and caudal to the pubic tubercle. The needle should then be rotated 30 degrees lateral and inserted toward the superior edge of the superior pubic ramus. ${ }^{[12]}$ Failure to block the obturator nerve along with the AON completely during a transurethral bladder surgery can lead to lifethreatening hemorrhage owing to the proximity of the overextended bladder to an accessory obturator artery. ${ }^{[17,18]}$ However, Akata et al. ${ }^{[18]}$ were unsure whether the inadequate anesthesia or lack of direct targeting for the AON caused the life-threatening hemorrhage. Akkaya et al. ${ }^{[12]}$ suggested that the best way to prevent injury is to plan for the presence of the AON regardless of the situation to ensure complete obturator nerve blockage.

\section{Conclusion}

We studied the AON and documented its origin, course and variants. A better understanding of this nerve's anatomy can lead to better outcomes following invasive procedures to the area.

\section{Acknowledgements}

The authors thank those who donated their bodies for anatomical study. There were no potential conflicts of interest. Author contributions: Conceived and designed the cadaver study and literature analysis: MT, RJO, RST. Performed the cadaver study: MP, BG. Analysis and interpretation of the data: MT, RJO, ML, RST. Contributed materials/analysis tools: MP, BG, RST. Drafted the article: MT, RST. Approved the final version to be published: MT, MP, BG, RJO, ML, RST. The views expressed herein are those of the authors and not necessarily those of their institutions. 


\section{References}

1. Swanson LW. Neuroanatomical terminology: a lexicon of classical origins and historical foundations. Oxford: Oxford University Press; 2015. p. 29.

2. Cruveilhier J. The anatomy of the human body. New York (NY): Harper and Brothers; 1844.

3. McMinn RMH. Last's anatomy: regional and applied. 9th ed., Marrickville (NSW), Australia, Elsevier; 2003. p. 397.

4. Bergman RA, Thompson SA, Afifi AK, Saddeh FA. Compendium of human anatomical variations. Baltimore: Urban and Schwarzenburg; 1988. pp 143-8.

5. Katritsis E, Anagnostopoulou S, Papadopoulos N. Anatomical observations on the accessory obturator nerve (based on 1000 specimens). Anat Anz 1980;148:440-5.

6. Eisler P. Der Plexus lumbosacralis des Menschen. Anat Anz 1891;6: 274-81.

7. Eisler P. Der Plexus lumbosacralis des Menschen. Abh naturforsch Ges Halle 1892;17: 279-364.

8. Bardeen CR, Elting AW. A statistical study of the variations in the formation and position of the lumbosacral plexus in man. Anat Anz 1901;19:124-8, 209-32.

9. Kaiser RA. 1949. Obturator neurectomy for coxalgia. An anatomical study of the obturator and the accessory obturator nerve. J Bone Joint Am 1949;31:815-19.

10. Woodburne RT. The accessory obturator nerve and the innervation of the pectineus muscle. Anat Rec 1960;136:367-9.

11. Webber RH. Some variations in the lumbar plexus of nerves in man. Acta Anat 1961;44:336-45.

12. Akkaya T, Comert A, Kendir S, Acar HI, Gumus H, Tekdemir I, Elhan A. Detailed anatomy of accessory obturator nerve blockade. Minerva Anestesiol 2008;74:119-22.

13. Anloague PA, Huijbregts P. Anatomical variations of the lumbar plexus: a descriptive anatomy study with proposed clinical implications. J Man Manip Ther 2009;17: e107-e114.

14. Quain J, Sharpey W, Thomson A, Cleland JG. Quain's elements of anatomy. 7 ed. The University of California: James Walton; 1867. p. $663-4$.

15. Ellis H. Demonstrations of anatomy. 11th ed. 1887. a, p. 543; b, p. 631.
16. Allen H, Shakespeare EO. A System of human anatomy: bones and joints. 2nd ed. H. C. Lea's Son \& Company; 1883. p. 566.

17. Atanassoff PG, Weiss BM, Brull SJ. Lidocaine plasma levels following two techniques of obturator nerve block. J Clin Anesth 1996;8: 535-9.

18. Akata T, Murakami J, Yoshinaga A. Life-threatening haemorrhage following obturator artery injury during transurethral bladder surgery: a sequel of an unsuccessful obturator nerve block. Acta Anaesthesiol Scand 1999;43:784-88.

19. Rohini M, Yogesh AS, Banerjee C, Goyal M. Variant accessory obturator nerve? A case report and embryological review. Journal of Medical and Health Sciences 2012;1:7-9.

20. Jirsch JD, Chalk CH. Obturator neuropathy complicating elective laparoscopic tubal occlusion. Muscle Nerve 2007;36:104-6.

21. Hollinshead WH. Anatomy for surgeons. Vol. 2: The thorax, abdomen \& pelvis. London: Cassell \& Co. Ltd.; 1956. p. 636-8.

22. Lennon RL, Horlocker TT. Mayo Clinic Analgesic pathway: peripheral nerve blockade for major orthopedic surgery and procedural training manual. Boca Raton (FL): CRC Press; 2006. p. 6.

23. Bonica J. Management of pain. Philadelphia (PA): Lippincott, Williams \& Wilkins; 2010. p. 1079.

24. De Sousa OM. Concideracoes anatomocirurgicas sobre nervo obturator acessorio. Rev Cir S Paulo 1942;7:399-402.

25. Sim IW, Webb T. Anatomy and anaesthesia of the lumbar somatic plexus. Anaesth Intensive Care 2004;32:178-87.

26. Standring S. Gray's anatomy. 40th ed. London: Churchill Livingstone; 2008. p. 1069-81.

27. Tubbs RS, Sheetz J, Salter G, Oakes WJ. Accessory obturator nerves with bilateral pseudoganglia in man. Ann Anat 2003;185:571-2.

28. Howell AB. The phylogenetic arrangement of the muscular system. Anat Rec 1936;66:295-316.

29. Yasar S, Kaya S, Temiz C, Tehli O, Kural C, Izci Y. Morphological structure and variations of lumbar plexus in human fetuses. Clin Anat 2014;27:383-8.

30. Bolk L. Beziehungen zwischen. Skelett, Muskulatur and Nerven der Extremitäten. Morphol Jahrb 1894;21:241-77.

31. Leche W. Muskulatur. Säugethiere. Mammalia. Dr. H. G. Bronn's Klassen und Ordnungen des Thierreichs 1900;6:649-919.

32. Grafenberg E. Die Entwickelung der Menschlichen Beckenmuskulatur. Anat Hefte 1904;23:431-93.

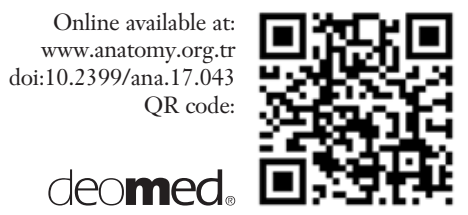

\author{
Correspondence to: R. Shane Tubbs, PhD, PA-C, MS, BS \\ Seattle Science Foundation, 550 17th Avenue, \\ Suite 600 , Seattle, WA 98122, USA \\ Phone: +1 2067326500 \\ e-mail: shanet@seattlesciencefoundation.org \\ Conflict of interest statement: No conflicts declared.
}

This is an open access article distributed under the terms of the Creative Commons Attribution-NonCommercial-NoDerivs 3.0 Unported (CC BY-NCND3.0) Licence (http://creativecommons.org/licenses/by-nc-nd/3.0/) which permits unrestricted noncommercial use, distribution, and reproduction in any medium, provided the original work is properly cited. Please cite this article as: Turgut M, Protas M, Gardner B, Oskouian RJ, Loukas M, Tubbs RS. The accessory obturator nerve: an anatomical study with literature analysis. Anatomy 2017;11(3):121-127. 